
published.

\title{
Estimating the Distributic $n$ of Lifetime Cumulative Radon Exposures for California Residents: A Brief Summary
}

\author{
Kai-Shen Liu, Yu-Lin Chang, Steven B. Hayward \\ Indoor Air Quality Program \\ Air \& Industrial Hygiene Laboratory \\ California Department of Health Services \\ Berkeley, California 94704
}

\author{
Ashok J. Gadgil, Anthony V. Nero, Jr. \\ Indoor Environment Program \\ Energy and Environment Division \\ Lawrence Berkeley Laboratory \\ University of California \\ Berkeley, California 94720
}

April 1992

This work was supported by the Director, Office of Energy Research, Office of Health and Environmental Research, Health Effects and Life Sciences Division of the U.S. Department of Energy under Contract No.DE-AC03-76SF00098.

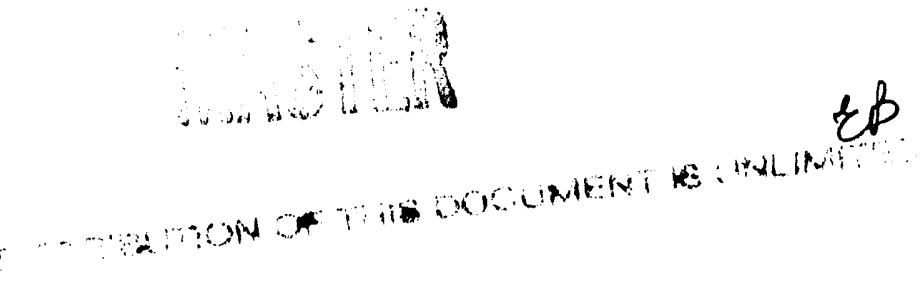


Estimating The Distribution of Lifetime Cumulative Radon Exposures for California Residents: A Brief Summary

Kai-Shen Liu, Yu-Lin Chang, Steven B. Hayward

Indoor Air Quality Program, Air \& Industrial Hygiene Laboratory, California Department of Health Services, Berkeley, CA 94704, U.S.A.

Ashok J. Gadgil, Anthony V. Nero, Jr.

Indoor Environment Program, Energy and Environment Division, Lawrence Berkeley Laboratory, Berkeley, CA 94720 , U.S.A.

Abstract: We have used data on residential radon concentrations in California, together with information on California residents' moving histories and time-activity patterns, to estimate the distribution of lifetime cumulative exposures to radon 222. This distribution was constructed using Monte Carlo techniques to simulate the lifetime occupancy histories - and associated radon exposures - of 10,000 California residents. For standard male and female lifespans, the simulation sampled from transition probability matrices representing changes of residence within and between six regions of California, as well as into and out of the other United States, and then sampled from the appropriate regional (or national) distribution of indoor concentrations. The resulting distribution of lifetime cumulative exposures has a significantly narrower relative width than the distribution of California indoor concentrations, with only a small fraction - lass than $0.2 \%$ - of the population having 
lifetime exposures equivalent to living during their lifetimes in a single home with a radon concentration of $148 \mathrm{~Bq} / \mathrm{m}^{3}$ or more. 
Introduction

Because people change residences during their lifetimes and have varied patterns of daily activity, the distribution of lifetime personal exposures to radon 222 and its decay products is not simply related to the distribution of current concentrations in residences. Experience indicates that the latter distribution typically has an approximately lognormal form. ${ }^{1}$ If people lived in only one home during their lifetimes, the distribution of individual exposures would be related by a simple factor to the concentration distribution (except for the effects of varying lengths of $1 \mathrm{ife}$ and time spent outside the home). For example, in the United States, where about 6 or $7 \%$ of single-family houses have radon concentrations exceeding $148 \mathrm{~Bq} / \mathrm{m}^{3}, 1$ if this were the only housing type, the sanie percentage of the population would have lifetime exposures corresponding to this indoor concentration, since in fact people would be occupying the same houses for their lifetimes.

However, the U.S. population is highly mobile, which for each person has the effect of averaging over the concentrations of a number of U.S. houses. Thus a person who has lived for some period in a house with very high concentrations will tend at other times to live in homes with lower levels, and the converse is true for a person living for some period with unusually low concentrations. In this way, concentrations at the extremes tend to be averaged with more typical values, leading to a narrower distribution and a smaller fraction of the population experiencing very high (or very low) lifetime exposures.

To illustrate the potential importance of occupancy history, a simple Monte Carlo calculation was recently performed, assuming that each member of the U.S. population moves every 7 years to a house with a concentration 
chosen randomly from the U.S. concentration distribution. ${ }^{2}$ The resulting distribution of exposures had, of course, an average corresponding to living for a lifetime in a house with the average indoor radon concentration (about $55 \mathrm{~Bq} / \mathrm{m}^{3}$ ), but only $0.6 \%$ of individual exposures corresponded to living at an average of $148 \mathrm{~Bq} / \mathrm{m}^{3}$ or more, an order of magnitude less than tne fraction of homes currently having levels this high.

Members of the population, however, do not move with a fixed frequency, nor do they move to a randomly selected house in the national housing stock. Thus a more accurate evaluation of the effects of mobility and other factors requires more compleite information and a methodology that takes account of the variation in behavior. We report an arialysis of results from California to explore the influence of mobility and timeactivity patterns on cumulative lifetime exposures to radon.

Understanding this question is important if we are to have any estimation of the fraction of the population experiencing higher-thanaverage lifetime exposures. This, in turn, ought to be an important factor in the adoption of objectives and strategies in programs for controlling exposures to indoor radon.

\section{Data and methodology}

The primary sets of information utilized in this analysis are results from independent representative surveys in California of: indoor radon concentrations, mobility, and time-activity patterns.

The indoor monitoring survey measured radon concentrations using etched-track detectors placed for a year in the living space of 310 homes. 3 The results were approximately lognormally distributed (although with a 
slight excess of high-concentration results), with a geometric mean (GM) of $31 \mathrm{~Bq} / \mathrm{m}^{3}$ and a geometric standard deviation (GSD) of 1.9. For this survey, the state was divided into six geophysical regions, for which significantly different distributions were found, with the following GMs (and GSDs): 24 $\mathrm{Bq} / \mathrm{m}^{3}(1.7), 48 \mathrm{~Bq} / \mathrm{m}^{3}(1.6), 27 \mathrm{~Bq} / \mathrm{m}^{3}(1.8), 81 \mathrm{~Bq} / \mathrm{m}^{3}(2.4), 43 \mathrm{~Bq} / \mathrm{m}^{3}$ (1.6), $29 \mathrm{~Bq} / \mathrm{m}^{3}(1.8)$.

The mobility survey, conducted specifically for this study, distributed questionnaires to a representative sampling of homes, resulting in lifetime moving histories for 1179 individuals from 507 current households. This provided information for current California residents on the annual probability of moving during their lives as a function of age (shown in Figure 1 for the entire state) and on the transition probabilities for moving within the same region, between regions, and from or to other states of the United States. The probability of being born outside of California was found to be $\mathbf{0 . 5 0 5}$.

Information on time-activity patterns was obtained from two earlier studies, one from questionnaires administered to a representative sampling of people with age greater than $11^{4}$ and another from questionnaires covering time spent inside and outside residences of 1373 people of al1 ages in 470 mobile home households, from a survey of indoor formaldehyde concentrations. ${ }^{5}$ The percentages of time spent inside residences from the two studies were essentially identical for ages greater than 11, but the formaldehyde survey lacked detailed information on various microenvironments, for which reason we used the information jointly for present purposes. For ages greater than 11, the average percentages of time spent in various locations were: $62 \%$ at home, $25 \%$ in other buildings, $8 \%$ in transit (including $1 \%$ not inside vehicles), and $5 \%$ outdoors. Those 
aged less than 5 and more than 65 spent approximate'y and additional 10\% time at home. For the present analysis, it was assumed that time-activity patterns and probability of moving had the same age dependence for all the regions.

Finally, information on birth rates, gender distributions, lifespans, and region of birth (if born outsied California) was obtained from the vital statistics for California. The probability of being born male was approximately 0.51 , and the lifespan of males and females were taken to be 73 and 80 years, respectively.

The basic approach for the simulation of population exposure was to construct the lifetime exposure for each of 10,000 hypothetical individuals. Once birthplace and gender were determined, exposure was calculated year by year for the person's lifespan by sampling from the appropriate indoor concentration distribution $\left(G M=33 \mathrm{~Bq} / \mathrm{m}^{3}\right.$ and $G S D=2.8^{1}$ if the person was at that point living outside California), then calculating the residential exposure of that year from the product of the sampled concentration and the percentage time spent at home characteristic of that age, and adding an estimate of the exposure accumulated outside the home. (For this purpose, the outdoor concentration was taken to be 7 $\mathrm{Bq} / \mathrm{m}^{3}$, and the concentration inside nonresidential buildings was taken to be the mean of the outdoor value and the regional indoor GM.) This Monte Carlo approach then continued by sampling from age and regional mobility probabilities to determine whether place of residence had changed during the next year, thus indicating whether a new selection had to be made from the appropriate regional concentration distribution. Exposure was accumulated until five years before the end of life (accounting in a nominal way for the 1 ung cancer latency period ${ }^{6}$ ). 
Two methods of sampling were used for determining an individual's residential radon concentration, one by sampling from the lognormal representation of the regional indoor radon distribution (parameterized by the GMs and GSDs given above), and the other by sampling directly with replacement from among the concentration results actually obtained from the monitoring survey in that region (called the "bootstrap" approach in the following).

Results

Characteristics of the distributions from the Monte Carlo simulations (in each case of 10,000 individuals) are shown in the top part of Table 1. For each apprcach - whether using lognormal sampling or the bootstrap method - two separate simulations were performed using sets of 10,000 individuals; the results are statistically indistinguishable from one another. Simulations of the exposure distributions were performed for several different assumptions, including no moving, where residents occupy the same house all their lives, moving every 7 years to a random house in the California distribution (comparable to the illustrative calculation performed earlier for the United States), and moving according to the Cal ifornia mobility results (called "Cal. move" in the Table), the distribution of main interest. The lognormal and bootstrap sampling approaches gave equivalent results for the simulations with the actual "moving" data.

The lognormal and bootstrap methods yield noticeably different results for the non-moving case since, aside from the effect of time spent outside the home, this case yields the same form as the indoor concentration distribution assumed. As noted above, the actual monitoring 
high concentrations as compared with a lognormal fit (corresponding to the lognormal exposure distribution).

The "high-exposure risk," given for each case in the Table, is the fraction of people whose exposure corresponds to living $100 \%$ time, for one's lifespan less five years, at concentrations of $148 \mathrm{~Bq} / \mathrm{m}^{3}$ or more. Note that the "bootstrap" non-moving result indicates $0.5 \%$ at "high exposure," in contrast to a lognormal result of about $0.2 \%$. For either sampling scheme, the moving result has a smaller percentage of people at high exposure than for no moving, with the difference being most substantial for the bootstrap results. The 7 -year moving result has essentially no (less than $0.01 \%$ of) people at high exposure iecause this fixed pattern of movement radically suppresses this tail, as had been suggested from the earlier results.

These smaller tails occur - in spite of the fact that the moving distribution has a larger mean exposure than the non-moving distribution because the width of the moving distribution, as indicated by the standard deviation, is significantly smaller. (The 7-year moving distribution has an even smaller standard deviation.) These results are consistent with those from a parallel analysis being performed for Minnesota - a state with higher indoor radon concentrations than California - where the width of the simulated exposure distribution, and the percentage in the tails, is considerably smaller than for the indoor concentration distribution. ${ }^{7}$ We note that the moving and 7 -year moving results have higher mean exposures than the non-moving results; this may occur because most of the California population is in the low-concentration areas, and permitting moving tends to average in the high-concentration regions to a greater degree. 
This work illustrates a methodology for simulating the lifetime exposure distribution to indoor radon, applied in this case to a state with lower-than-average radon concentrations. Still, the main features of the analysis and the resulting distributional characteristics are indicative of the important difference between distributions of lifetime exposures and of indoor concentrations. The importance of this distinction ought to be even greater when considering the United States as a whole, with its widely variable indoor concentrations and moving patterns. However, the ability to simulate these exrosures may be limited by the data available. Although parameters of the indoor concentration distribution have been available for some time, ${ }^{1}$ and this information is improving with the availability of results from the Environmental Protection Agency's National Residential Radon Survey, ${ }^{8}$ the required information on moving patterns for the U.S. as a whole has not been developed. It may be necessary, therefore, to utilize less complete information on mobility, such as that available from the U.S. census, the approach taken in the analysis of radon exposures for Minnesota residents. ${ }^{7}$

This work was supported by the Director, Office of Energy Research, Office of Health and Environmental Research, Health Effects and Life Sciences Division of the U.S. Department of Energy under Contract No. DEAC03-76SF00098. 


\section{References}

1. Nero, A. V., Schwehr, M. B., Nazaroff, W. W., and Revzan, K. L. Distribution of Airborne Radon-222 Concentrations in U. S. Homes. Science 234, 992-997 (1986).

2. Nero, A. V., Gadgil, A. J., Nazaroff, W. W., and Revzan, K. L. Indoor Radon and Decay Products: Concentrations, Cúuses, and Control Strategies. DOE/ER-0480P, U.S. Department of Energy, Washington,DC, 1990.

3. Liu, K. S., Hayward, S. B., Girman, J. R., Moed, B. A., and Huang, F. J. Annual Average Radon Concentrations in California Residences. J. Air Waste Manage. Assoc. 41, 1207-1212 (1991).

4. Jenkins, P. L., Phillips, T. J., and Mulberg, E. J. Activity Patterns of Californians: Use of and Proximity to Indoor Pollutant Sources. In Indoor Air ' 90 (Proc. 5th Int. Conf. on Indoor Air and Climate, Toronto, Canada, 1990); Wiley, J. A, Robinson, John P., et al. Activity Patterns of California Residents. California Air Resources Board, Sacramento, CA, 1991.

5. Liu, K. S., Hayward, S. B., Kulasingam, G., Chang, B., and Sexton, K. Estimation of Formaldehyde Exposure for Mobile Home Residences. Proc. 79th Annual Meeting Air Pollution Control Association, Minneapolis, MN, June 1986. 
6. U.S. National Research Council. Health Effects of Radon and other Internally Deposited Alpha Emitters. National Academy Press, Washington, DC, 1988.

7. Gadgil, A. J., Rein, S., Nero, A. V., and Wollenberg, H. The Distribution of Lifetime Radon Exposures for Minnesota Residents. Draft Report, Lawrence Berkeley Laboratory, Berkeley, CA, 1992.

8. Marcinowski, F. National Residential Radon Survey. NREV, paper 131, 1991. 
Figure Caption

Figure 1. Annual probability of moving as a function of age for all California residents. 


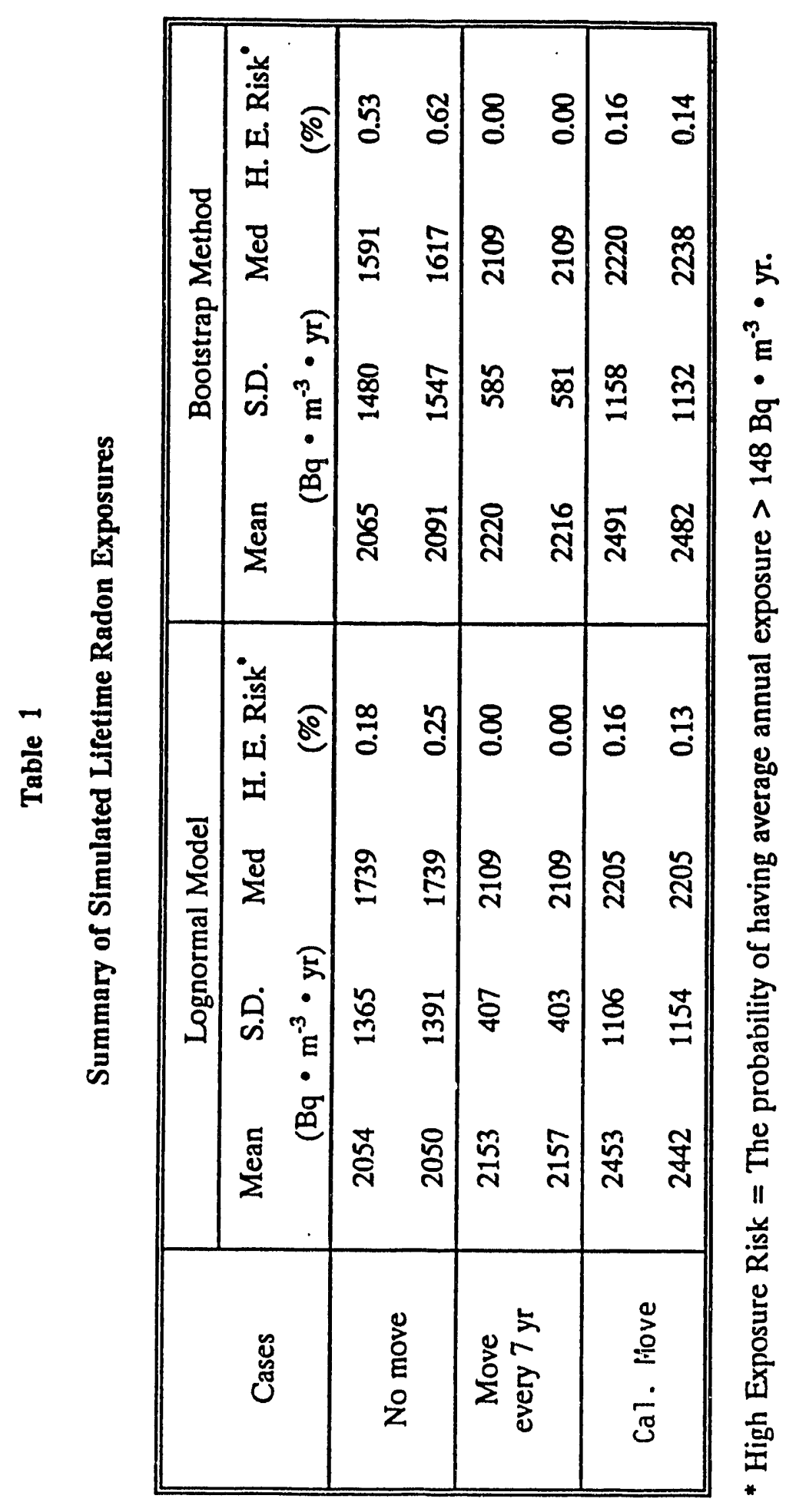




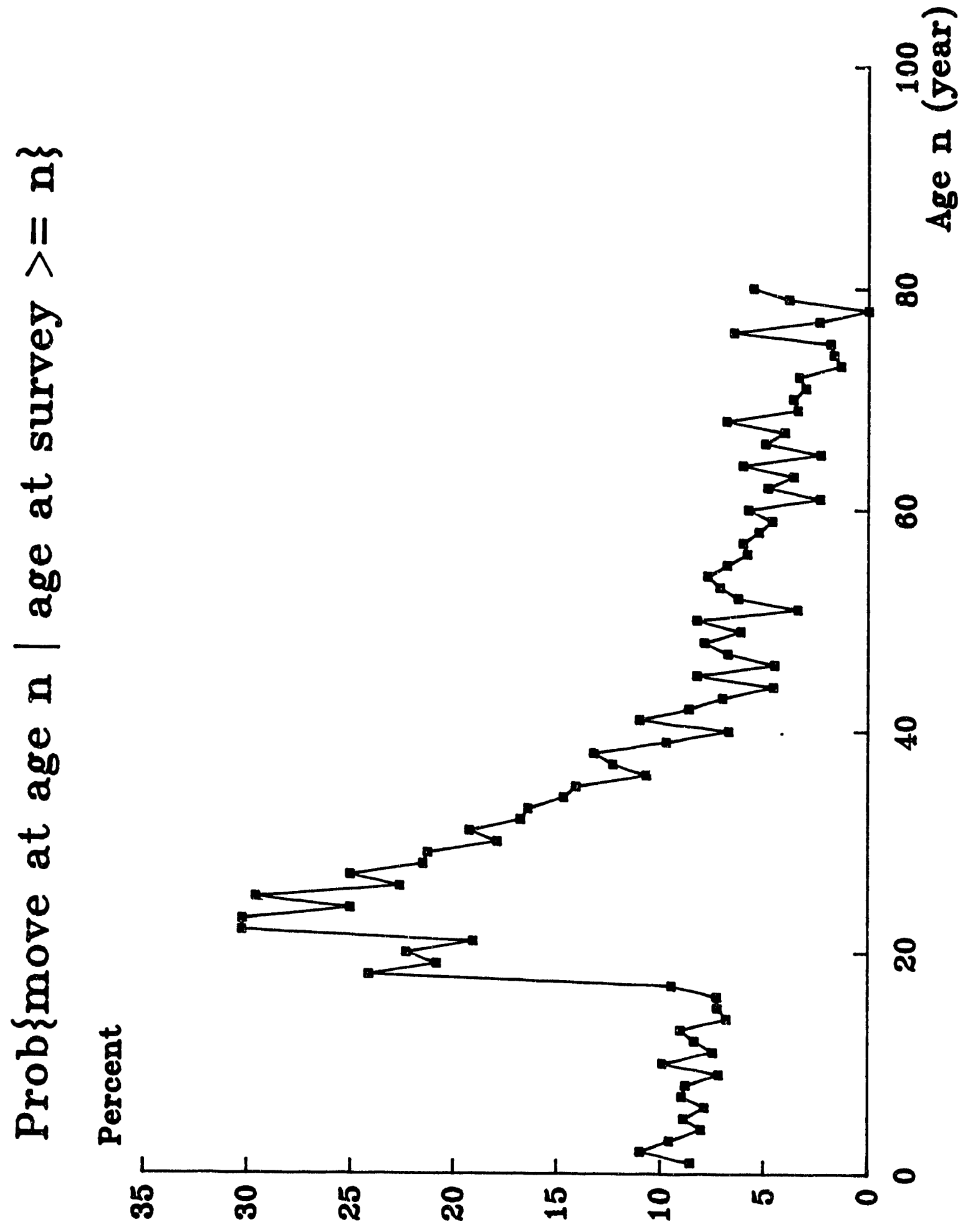




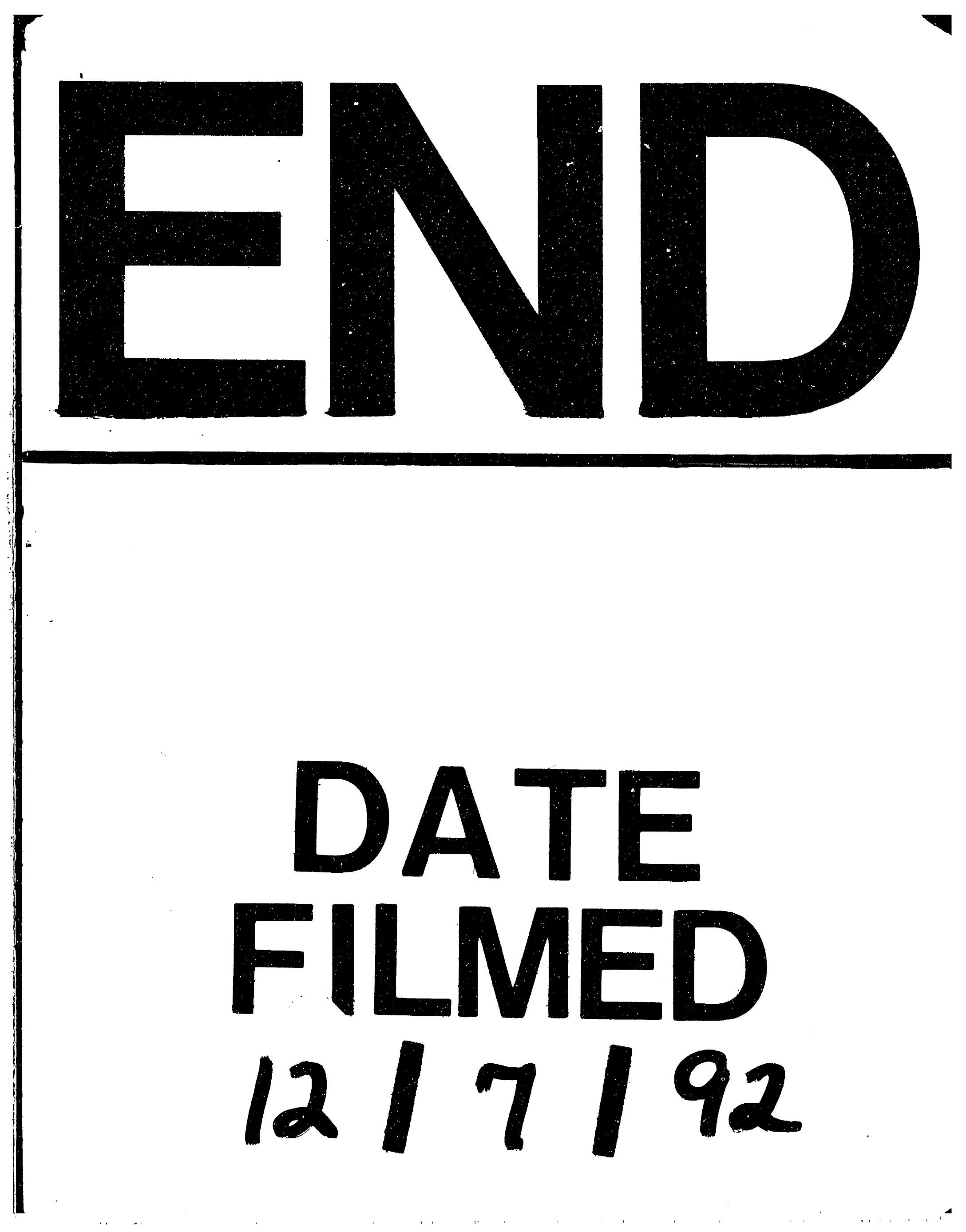


